\title{
Carrier Risk Calculations for Recessive Diseases when all the Mutant Alleles are not Detectable
}

\author{
Mahnaz Khattak \\ Jinnah College for Women, University of Peshawar, Pakistan \\ Shuhrat Shah \\ Department of Statistics, University of Peshawar, Pakistan \\ Bahrawar Jan \\ Department of Statistics, University of Peshawar, Pakistan
}

\begin{abstract}
There are certain recessive diseases in which some of mutations causing the disease, can be detected using the genetic probabilities. For counseling purposes, the probability that, a consultand known not to have a detectable mutation, a carrier needs to be calculated with as much accuracy as possible.

A method for the carrier risk calculation is proposed, which is based on information on the parents, one or two sibs and one or two children as well as on the spouse of the consultand in terms of positive or negative test results only, since genotype configurations for all of them may not be available in practice.

For a particular disease, the carrier risk is calculated by its incidence and the proportion of the mutations that are detectable, the table once produced can be used for any family of the types included.
\end{abstract}

\section{Introduction}

It was observed that certain recessive diseases, such as Cystic fibrosis, Congenital adrenal hyper-plasia, Sub acute thyroid, Lymphatic leukemia, Schizophrenia, Juvenile arthritis etc, showing the test result for the disease being negative, carried by the person and appeared in the children or grand children or great grand children. Lange and Elson (1975) presented likelihood calculations for simple and complex pedigrees. Canning et. al (1976) calculated risk factors and likelihoods for familial diseases. Edwards (1990) presented a procedure for risk analysis in cystic fibrosis. Slack et al. (1990) presented carrier risks calculation for individuals known not to have the $\Delta 508$ mutations for cystic fibrosis, when a first cousin, an uncle or aunt or a sibling is known to be a carrier.

There are many people with Cystic fibrosis whose mutations have not been identified. In other words, all of the genetic errors that cause the disease have not been discovered. Because not all mutations are detectable, a person can still be a carrier even if no mutations were found by carrier testing (Children's Hospital Boston, 2001).

The birth of a child with Cystic fibrosis is often a total surprise to a family, since most of the time there is no previous family history of Cystic fibrosis. Many autosomal recessive conditions occur this way. Since both parents are healthy, 
they had no prior knowledge that they carried the gene, nor that they passed the gene to the pregnancy at the same time (St. Louis Children's Hospital, 2003).

These are precisely the problems that mutation testing is supposed to address. However, the actual changes in carrier risk for tested and untested family members following mutation testing, in the clinical practice setting, have not yet been fully described (Watson' et al, 2003).

Recessive disorders are associated with inheriting two copies of an identical mutation; cousins are more likely to inherit an identical mutation because of sharing a pair of grandparents, one of whom might carry a mutation that they could pass on to their children and grandchildren (Shah, 2003).

For different relative cases, a method is presented in this study to calculate carrier risk, with the assumption of no detectable mutations in the parents as well as children. Furthermore it is assumed that the parents and spouse of the consultand are not having the disease and so did not tabulated the probabilities of the children having the disease.

\section{Proposed Method of Carrier Risk Calculation}

In this study a method is proposed to calculate carrier risk, using information available about percentages of detectable mutations in the population, genotype of the consultand and the disease status of the near relatives of the consultand.

The carrier risk calculations are based on information available on the parents, one or two sibs and one or two children. When the test results are available on the children, the test status of the spouse of the consultand is relevant and may also be included in calculations. Since in practice, genotyping configurations for all of the relatives is not available, therefore information about relatives are considered only in terms of test results whether positive or negative.

A hypothetical data on certain specific disease with $20 \%$ detectable mutations has been used for calculation of carrier risk.

The categories used for the alleles at the disease locus as normal, $\mathrm{N}$; a detectable mutant, $\mathrm{D}$; and an undetectable mutant, $U$. The six resulting genotypes have the implications shown in Table.1, where, ' + ' indicates mutations detectable, '-', indicates mutations undetectable, 'Disease', indicates affected by the disease, and 'Carrier', a carrier of the disease. The frequency of the six genotypes is based upon the hypothetical data in Table-1 with $20 \%$ of the mutations detectable.

To calculate the probability that the consultand $\mathrm{C}$, has the genotype $\mathrm{NU}$ and so carries an undetectable mutation when he or she has negative test and so is either NN or NU, $P(C$ is $N U / I)$ can be obtained as;

$$
P(C \text { is } N U / I)=\frac{P(C \text { is } N U \text { and } I)}{P(I)}
$$


Where ' $I$ ' indicates any test or disease information available about the relatives of the consultand. Similarly the probability that the consultand $\mathrm{C}$, has the genotype NN

$$
P(C \text { is } N U / I)=\frac{P(C \text { is } N N \text { and } I)}{P(I)}
$$

The odd ratio that $\mathrm{C}$ is $\mathrm{NU}$ or $\mathrm{NN}$ is

$$
\frac{P(C \text { is } N U / I)}{P(C \text { is } N U / I)}=\frac{P(C \text { is } N U \text { and } I)}{P(C \text { is } N N \text { and } I)}
$$

The possible relatives of $C$ are Parent1(P1), Parent2( P2), Spouse (S), Sib1(S1), Sib2(S2), Child1 (C1) and Child2 (C2). The odd ratio can be written as;

$$
\frac{P(C \text { is } N U / I)}{P(C \text { is } N U / I)}=\frac{P(C \text { is } N U, P 1, P 2 . S 1, S 2, S, C 1, C 2)}{P(C \text { is } N N, P 1, P 2 . S 1, S 2, S, C 1, C 2)}
$$

Since $\mathrm{C}$ is either NU or NN and parents and sibs are only linked to the children through $\mathrm{C}$, therefore the conditional approach can be established. That is

$$
\begin{aligned}
& \frac{P(C \text { is } N U / I)}{P(C \text { is } N U / I)}=\frac{[P(C \text { is } N U, P 1, P 2 . S 1, S 2) \times P(S, C 1, C 2 / C \text { is } N U)]}{[P(C \text { is } N N, P 1, P 2 . S 1, S 2) \times P(S, C 1, C 2 / C \text { is } N N)]} \\
& \frac{P(C \text { is } N U / I)}{P(C \text { is } N U / I)}=\left[\frac{P(C \text { is } N U, P 1, P 2 . S 1, S 2)}{P(C \text { is } N N, P 1, P 2 . S 1, S 2)}\right] \times\left[\frac{P(S, C 1, C 2 / C \text { is } N U)}{P(S, C 1, C 2 / C \text { is } N N)}\right] \\
& \mathrm{R}=\mathrm{P} \times \mathrm{M}
\end{aligned}
$$

Where $P$ is the odds ratio that $C$ is NU compared with $C$ is NN based only on information about C's parents and sibs. The Table-2 contain the detailed calculation for this odd ratio.

The second ratio in equation-1, $\mathbf{M}$ is the conditional odds ratio if information is also available about C's spouse $S$ and children $\mathrm{C} 1$ and $\mathrm{C} 2$ which works as a multiplier/weight to $\mathbf{P}$. Table-3 has the required calculation for $\mathrm{M}$.

It can be observed that if information about C's spouse $S$ and children $\mathrm{C} 1$ and C2 are ignored i.e. $M=1$ then $R=P$.

From the odd ratio $R=\frac{p(C \text { is } N U)}{P(c \text { is } N N)}, P(C$ is $N U)$ is calculated as

$$
P(C \text { is } N U)=\frac{R}{1+\mathrm{R}} .
$$

The probability that the consultand $\mathrm{C}$ carries an undetectable disease alleles, are shown in Table-4, Table-5, and Table-6 for all the important combinations of information about parents, sibs, spouse, children and aunt/uncle. 
The table once produced can be used for any family of the types included, for any particular disease, which is recessive in type, and is characterized only by its incidence and the proportion of the mutations that are detectable.

In case of first cousins intending to become couple parents are referred for counseling on the risks they run for their children having certain genetic diseases. If both first cousins have been tested and found to have no detectable mutations and nothing else is known about their relatives, except that their parents, one or two sibs, spouse, one or two children have been tested and found to be either positive or negative for the disease under consideration, then the probability that they carry the disease can be calculated. The tables can further be used to calculate the disease and carrier risk for the first child of the couple of first cousins.

It is obvious from the results that the children of the parents who are near relatives have higher probabilities for the disease or carrier of the disease as compared to those parents who are not near relatives.

\section{Conclusion}

In this study a method is proposed to calculate the carrier risk based on information available about near relatives in terms of test result positive or negative only.

A hypothetical data on certain Joiner Arthritis disease with $20 \%$ detectable mutations has been used to calculate carrier risk despite negative test result for different options about parents, sibs, spouse and children.

In case of near relatives marriages, the couple is advised for counseling on the risks they run for their children having certain genetic diseases. This study provide the calculation of probabilities of carrying a genetic disease, if both have been tested and found to have no detectable mutations and nothing else is known about their relatives, except that their parents, one or two sibs, spouse, one or two children have been tested and found to be either positive or negative for the disease under consideration. It can be concluded that the children of the parents who are near relatives are more likely to have the disease or carrier of the disease than those who are not relatives.

\section{References}

1. Lange, K. and Elson, R.C. (1975). Extensions to pedigree analysis. Likelihood calculations for simple and complex pedigrees. Hum. Hared. 25, 95-105.

2. Cannings, C., Skolnick, H.H., and Sridharan, R. (1976). Calculation of risk factors and likelihood for familial diseases. Comp and Biom. Res. 9, 393-407.

3. Children's Hospital Boston, (2001). Integrating Genetic Testing into Practice. 
4. Edwards, J.H. (1990). The slash sheet: a simple procedure for risk analysis in cystic fibrosis. Am. J. Hum. Genet. 47, 1024-1028.

5. Shaw, A. (2003). The impact of genetic risk on UK Pakistani families. The Encyclopedia of the Human Genome, Nature Publishing Group.

6. Slack, J., Houlston, R.S. and Marteau, T. (1990). Identification of the cystic fibrosis gene. Br. Med. J. 300: 812.

7. St. Louis Children's Hospital, (2003). The Genetics of Cystic Fibrosis.

8. Watson, P., Narod, S.A., Fodde, R., Wagner, A., Lynch, J.F. and Tinley, S.T. (2003). Carrier risk status changes resulting from mutation testing in hereditary non-polyposis colorectal cancer and hereditary breast-ovarian cancer Journal of Medical Genetics; 40:591-596.

Table 1: Hypothetical data

\begin{tabular}{|cccl|}
\hline Genotype & Proportion & Test result & Disease / carrier Status \\
\hline NN & 0.350 & - & - \\
\hline DD & 0.044 & + & Disease \\
\hline UU & 0.053 & - & Disease \\
\hline UD & 0.042 & + & Disease \\
\hline NU & 0.400 & - & Carrier \\
\hline ND & 0.111 & + & Carrier \\
\hline & 1.000 & & \\
\hline
\end{tabular}

Table 2: $\quad$ Odds ratios, ' $P$ ' for $P(C$ is $N U) / P(C$ is $N N)$, from Parental and Sib Information (Tested Parents and Sibs with only positive or negative test results)

\begin{tabular}{|ccccccc|}
\hline $\begin{array}{c}\text { Sibs } \\
\text { Parents }\end{array}$ & No sibs & One -ve & Two -ve & One +ve & $\begin{array}{l}\text { One +ve, } \\
\text { one -ve }\end{array}$ & Two +ve \\
\hline-- & 0.7314 & 0.5851 & 0.4861 & 0.1463 & 0.1170 & 0.0293 \\
\hline-+ & 0.1829 & 0.1463 & 0.1170 & 0.0366 & 0.0293 & 0.0073 \\
\hline++ & 0.0457 & 0.0366 & 0.0293 & 0.0091 & 0.0073 & 0.0018 \\
\hline
\end{tabular}

Table 3: Odds ratio Multipliers, ' $M$ ' for the Odd Ratio from Children and Spouse information; (Tested children and spouse with only positive or negative results for the disease, are included)

\begin{tabular}{|c|c|c|c|c|c|c|}
\hline $\begin{array}{l}\text { Children } \\
\text { Spouse }\end{array}$ & None & One -ve & Two -ve & One +ve & $\begin{array}{l}\text { One -ve, } \\
\text { One +ve }\end{array}$ & Two + ve \\
\hline Negative & 1.1429 & 0.7314 & 0.5851 & 0.1829 & 0.1463 & 0.0366 \\
\hline Positive & 1.1429 & 0.1829 & 0.1463 & 0.0457 & 0.0366 & 0.0091 \\
\hline
\end{tabular}


Table 4: Probability of being a Joiner Arthritis carrier despite negative test (P1, P2 one negative and one positive)

\begin{tabular}{|llllllll|}
\hline Children & & None & one -ve & Two -ve & One +ve & $\begin{array}{c}\text { One -ve, } \\
\text { One +ve }\end{array}$ & Two +ve \\
\cline { 1 - 6 } Sibs & Spouse & & & & & 0.0261 & 0.0067 \\
None & Negative & 0.1723 & 0.1180 & 0.0967 & 0.0324 & 0.0261 & 0.0017 \\
\hline One -ve & Positive & 0.1723 & 0.0324 & 0.0261 & 0.0772 & 0.0067 & 0.0054 \\
& Positive & 0.1432 & 0.0967 & 0.0789 & 0.0261 & 0.0210 & 0.0054 \\
\hline Two -ve & Negative & 0.1179 & 0.0261 & 0.0210 & 0.0067 & 0.0054 & 0.0013 \\
& Positive & 0.1179 & 0.0210 & 0.0168 & 0.0053 & 0.0043 & 0.0011 \\
\hline One +ve & Negative & 0.0103 & 0.0067 & 0.0053 & 0.0017 & 0.0013 & 0.0003 \\
& Positive & 0.0103 & 0.0017 & 0.0013 & 0.0004 & 0.0003 & 0.0002 \\
\hline One -ve, & Negative & 0.0324 & 0.0210 & 0.0168 & 0.0054 & 0.0043 & 0.0011 \\
One +ve & Positive & 0.0324 & 0.0054 & 0.0043 & 0.0013 & 0.0011 & 0.0003 \\
\hline Two +ve & Negative & 0.0083 & 0.0053 & 0.0043 & 0.0013 & 0.0011 & 0.0003 \\
& Positive & 0.0083 & 0.0013 & 0.0011 & 0.0003 & 0.0003 & 0.0001 \\
\hline
\end{tabular}

Table 5: Probability of being a Joiner Arthritis (JA) carrier despite negative test for both $\mathrm{P} 1$ and $\mathrm{P} 2$ positive

\begin{tabular}{|c|c|c|c|c|c|c|c|}
\hline \multicolumn{2}{|l|}{ Children } & \multirow[t]{2}{*}{ None } & \multirow[t]{2}{*}{ One -ve } & \multirow[t]{2}{*}{ Two -ve } & \multirow[t]{2}{*}{ One +ve } & \multirow{2}{*}{$\begin{array}{l}\text { One -ve, } \\
\text { One +ve }\end{array}$} & \multirow[t]{2}{*}{ Two +ve } \\
\hline Sibs & Spouse & & & & & & \\
\hline & Negative & 0.0496 & 0.0320 & 0.0260 & 0.0084 & 0.0067 & 0.0017 \\
\hline None & Positive & & 0.0084 & 0.0067 & 0.0021 & 0.0017 & 0.0004 \\
\hline \multirow[t]{2}{*}{ One -ve } & Negative & 0.0401 & 0.0260 & 0.0214 & 0.0067 & 0.0054 & 0.0013 \\
\hline & Positive & & 0.0067 & 0.0054 & 0.0017 & 0.0013 & 0.0003 \\
\hline \multirow[t]{2}{*}{ Two -ve } & Negative & 0.0324 & 0.0214 & 0.0171 & 0.0054 & 0.0043 & 0.0011 \\
\hline & Positive & & 0.0054 & 0.0043 & 0.0013 & 0.0011 & 0.0003 \\
\hline \multirow[t]{2}{*}{ one +ve } & Negative & 0.0103 & 0.0067 & 0.0053 & 0.0017 & 0.0013 & 0.0003 \\
\hline & Positive & & 0.0017 & 0.0013 & 0.0004 & 0.0003 & 0.0001 \\
\hline \multirow{2}{*}{$\begin{array}{l}\text { One -ve, } \\
\text { one +ve }\end{array}$} & Negative & 0.0083 & 0.0053 & 0.0043 & 0.0013 & 0.0011 & 0.0003 \\
\hline & Positive & & 0.0013 & 0.0011 & 0.0003 & 0.0003 & 0.0001 \\
\hline \multirow[t]{2}{*}{ Two +ve } & Negative & 0.0021 & 0.0013 & 0.0011 & 0.0003 & 0.0003 & 0.0001 \\
\hline & Positive & & 0.0003 & 0.0003 & 0.0001 & 0.0001 & 0.0000 \\
\hline
\end{tabular}

Table 6: Probability of being a Joiner Arthritis (JA) carrier despite negative test for both $\mathrm{P} 1$ and $\mathrm{P} 2$ negative

\begin{tabular}{|c|c|c|c|c|c|c|c|}
\hline \multicolumn{2}{|l|}{ Children } & \multirow[t]{2}{*}{ None } & \multirow[t]{2}{*}{ one-ve } & \multirow[t]{2}{*}{ two-ve } & \multirow[t]{2}{*}{ One +ve } & \multirow{2}{*}{$\begin{array}{l}\text { One -ve, } \\
\text { One +ve }\end{array}$} & \multirow[t]{2}{*}{ Two +ve } \\
\hline Sibs & Spouse & & & & & & \\
\hline & Negative & 0.4553 & 0.3483 & 0.2997 & 0.1180 & 0.0967 & 0.0261 \\
\hline None & Positive & & 0.1180 & 0.0967 & 0.0323 & 0.0261 & 0.0067 \\
\hline \multirow{2}{*}{ One -ve } & Negative & 0.4007 & 0.2997 & 0.2550 & 0.1070 & 0.0789 & 0.0214 \\
\hline & Positive & & 0.0967 & 0.0789 & 0.0268 & 0.0210 & 0.0053 \\
\hline \multirow[t]{2}{*}{ Two -ve } & Negative & 0.3485 & 0.2551 & 0.2150 & 0.0856 & 0.0685 & 0.0171 \\
\hline & Positive & & 0.2796 & 0.0641 & 0.0240 & 0.0171 & 0.0043 \\
\hline \multirow{2}{*}{ One +ve } & Negative & 0.1432 & 0.0967 & 0.0789 & 0.0268 & 0.0214 & 0.0054 \\
\hline & Positive & & 0.0261 & 0.0210 & 0.0067 & 0.0054 & 0.0013 \\
\hline \multirow{2}{*}{$\begin{array}{l}\text { One -ve, } \\
\text { One +ve }\end{array}$} & Negative & 0.1179 & 0.07889 & 0.0641 & 0.0214 & 0.0171 & 0.0043 \\
\hline & Positive & & 0.0214 & 0.0168 & 0.0053 & 0.0043 & 0.0011 \\
\hline \multirow[t]{2}{*}{ Two +ve } & Negative & 0.0324 & 0.0214 & 0.0168 & 0.0053 & 0.0043 & 0.0011 \\
\hline & Positive & & 0.0054 & 0.0043 & 0.0014 & 0.0011 & 0.0003 \\
\hline
\end{tabular}

